\title{
Experimental Transmission of Ovine Herpesvirus-2 in Sheep
}

\author{
Tomoko NISHIMORI $^{1)}$, Ryoko ISHIHARA ${ }^{1)}$, Toru KANNO ${ }^{1)}$, Gamini L. JAYAWARDANE ${ }^{1 / \#}$, Kei NISHIMORI ${ }^{1)}$, \\ Ikuo UCHIDA $^{1)}$ and Kunitoshi IMAI ${ }^{2)}$ \\ ${ }^{1)}$ Hokkaido Research Station, National Institute of Animal Health, Hitsujigaoka 4, Toyohira, Sapporo 062-0045, ${ }^{2}$ National Institute of \\ Animal Health, Kannondai 3-1-5, Tsukuba, Ibaraki 305-0856, Japan
}

(Received 20 January 2004/Accepted 12 May 2004) ABSTRACT. Transmission of ovine herpesvirus-2 (OvHV-2) in sheep via natural contact and nasal secretions was examined. OvHV-2-free
lambs were produced by separating newborn lambs from their mothers within 5 days of birth and raising them in an isolation facility.
Transmission experiments via natural contact were conducted by keeping OvHV-2-free lambs with OvHV-2-infected sheep of different
ages. Six of the infected ewes in this experiment were pregnant and gave birth during the experimental period. OvHV-2 was not trans-
mitted from the adult sheep, though viral DNA was consistently detected in their peripheral blood leukocytes (PBL). On the othe $\mathrm{r}$ hand,
OvHV-2 was transmitted from recently infected lambs to sheep at 10 or 12 weeks after the onset of contact. In addition, we attempted
the experimental transmission of OvHV-2 via nasal secretions, by transferring nasal washings from infected sheep to the nostrils of unin-
fected sheep. Sheep receiving the nasal washings from infected adult sheep maintained their negative status for 15 months, whereas
sheep receiving nasal washings from recently infected lambs acquired OvHV-2 by 8 months. The results of these experiments support
that OvHV-2 is more easily transmitted to negative sheep by recently infected lambs than by adult sheep. Further, it is supposed that
the nasal cavity is a portal for entry and shedding of infectious OvHV-2 in sheep.

KEY WORDS: malignant catarrhal fever, nasal secretion, ovine, ovine herpesvirus-2, transmission.

J. Vet.Med. Sci. 66(10): 1171-1176, 2004

Malignant catarrhal fever (MCF) is a sporadic but often fatal disease of cattle, deer, and other large ruminants. There are two very similar clinical forms of this disease: wildebeest-derived MCF (WD-MCF) and sheep-associated MCF (SA-MCF). WD-MCF is caused by alcelaphine herpesvirus-1 (AlHV-1), which asymptomatically infects the reservoir host, the wildebeest. The virus has been isolated and classified as a member of the subfamily Gammaherpesvirinae [21]. There have been many reports of transmission of AlHV-1 in wildebeests [16, 20]. AlHV-1 crosses the placenta in some cows, and the calf is born infected with the virus. AlHV-1 infection occurs during the perinatal period $[18,19]$, and infected wildebeest calves shed the infectious virus in nasal or ocular secretions, primarily during the first 3 months of life [17].

The agent of SA-MCF, designated as ovine herpesvirus-2 $(\mathrm{OvHV}-2)$, is closely related antigenically to and shares DNA homology with AlHV-1 [3,5]. OvHV-2 has spread worldwide in sheep and has been identified as a main cause of MCF in ruminants. However, OvHV-2 has not been isolated in an in vitro culture system. In addition, the transmission patterns of OvHV-2 are not yet completely understood. Experimental transmission of OvHV-2 from sheep to susceptible hosts such as cattle and deer has not been always successful. We previously reported contact transmission of OvHV-2 from infected sheep to Japanese deer and cattle [10]. One of the two deer developed clinical signs of MCF, whereas the other deer and the cattle were not infected with OvHV-2.

\# Present address: Jayawardane, G.L., Dept. of Medical Microbiology and Genito-Urinary Medicine, University of Liverpool, Duncan Building, Daulby Street, Liverpool L69 3GA, UK.
On the other hand, transmission of OvHV-2 among sheep has been recently reported. All adult sheep living under typical flock conditions are considered to be infected with the virus, though the majority of newborn lambs are not infected. When lambs are separated from the flock at an early age, they can be raised free of the virus [12]. In contrast, most of the lambs raised under typical flock conditions are infected with the virus by the time they are 1-year-old [14]. Some investigators assert that SA-MCF is more common during the lambing season [4]. Therefore, it has been hypothesized that lambing stress activates the latent virus in ewes and causes them to shed the infectious virus [16]. However, the transmission route of OvHV-2 is not yet clear. Although some reports have indicated that the number of copies of OvHV-2 DNA present in nasal secretions is higher than that in peripheral blood leukocytes (PBL) [6, 11], it has not been confirmed that nasal secretions contain the infectious virus.

This study describes the production of OvHV-2-free lambs and the results of experimental transmission of the virus via natural contact and nasal secretions.

\section{MATERIALS AND METHODS}

OvHV-2-free sheep: This study was carried out over 3 years. In total, 14 Corriedale lambs born to OvHV-2infected ewes were separated from their mothers within 5 days of birth and raised in an isolation facility. They were checked regularly for the presence of OvHV-2 DNA in PBL and nasal secretions by the polymerase chain reaction (PCR) method described below. All 14 lambs were PCR-negative at the beginning of the transmission experiments. They 
Table 1. Experimental design for transmission of OvHV-2 in sheep

\begin{tabular}{|c|c|c|c|c|c|c|}
\hline Transmission & Exp. No. & Sheep No. & OvHV-2 & Sex & $\mathrm{Age}^{\mathrm{g})}$ & Period \\
\hline \multirow[t]{20}{*}{ I. Contact } & \multirow{2}{*}{1} & 955 & + & 8 & $3 Y$ & \multirow{2}{*}{8 months } \\
\hline & & 146 & - & 오 & $5 \mathrm{M}$ & \\
\hline & \multirow{2}{*}{2} & $957^{\mathrm{a})}$ & + & 우 & $3 Y$ & \multirow{2}{*}{8 months } \\
\hline & & 116 & - & $0^{3}$ & $11 \mathrm{M}$ & \\
\hline & \multirow{7}{*}{3} & $148^{\text {b) }}$ & + & 우 & $8 \mathrm{Y}$ & \multirow{7}{*}{6 months } \\
\hline & & $149^{b)}$ & + & 우 & $8 \mathrm{Y}$ & \\
\hline & & $150^{b)}$ & + & 우 & $8 \mathrm{Y}$ & \\
\hline & & $151^{\mathrm{b})}$ & + & 우 & $8 \mathrm{Y}$ & \\
\hline & & $152^{\mathrm{b})}$ & + & 우 & $7 Y$ & \\
\hline & & 140 & - & 우 & $9 \mathrm{M}$ & \\
\hline & & 143 & - & 우 & $9 \mathrm{M}$ & \\
\hline & \multirow{5}{*}{4} & $170^{\mathrm{c})}$ & + & 우 & $3 \mathrm{M}$ & \multirow{5}{*}{3 months } \\
\hline & & $171^{\mathrm{c})}$ & + & 우 & $3 \mathrm{M}$ & \\
\hline & & $172^{\mathrm{c})}$ & + & 우 & $3 \mathrm{M}$ & \\
\hline & & 165 & - & 우 & $4 \mathrm{M}$ & \\
\hline & & 167 & - & 우 & $4 \mathrm{M}$ & \\
\hline & \multirow{4}{*}{5} & $165^{\mathrm{d})}$ & + & 우 & $7 \mathrm{M}$ & \multirow{4}{*}{4 months } \\
\hline & & $167^{\mathrm{d})}$ & + & 우 & $7 \mathrm{M}$ & \\
\hline & & 140 & - & 우 & $1.5 \mathrm{Y}$ & \\
\hline & & 143 & - & 오 & $1.5 \mathrm{Y}$ & \\
\hline \multirow[t]{4}{*}{ II. Nasal secretions } & \multirow{2}{*}{6} & $114^{\mathrm{e})}$ & - & $\sigma^{7}$ & $11 \mathrm{M}$ & \multirow[b]{2}{*}{15 month } \\
\hline & & $117^{\mathrm{e})}$ & - & 우 & $11 \mathrm{M}$ & \\
\hline & \multirow{2}{*}{7} & $166^{\mathrm{f})}$ & - & $0^{7}$ & $4 \mathrm{M}$ & \multirow{2}{*}{9 months } \\
\hline & & $168^{\mathrm{f})}$ & - & $\sigma^{7}$ & $3 \mathrm{M}$ & \\
\hline \multirow{4}{*}{ III. Control } & \multirow{2}{*}{8} & 113 & - & 우 & & \multirow{2}{*}{3 years } \\
\hline & & 115 & - & $\sigma^{3}$ & & \\
\hline & \multirow{2}{*}{9} & 163 & - & 우 & & \multirow{2}{*}{1 year } \\
\hline & & 164 & - & 우 & & \\
\hline
\end{tabular}

a) Ewe \#957 gave birth at the 8th month.

b) Ewes \#148-\#152 gave birth at the 2nd month.

c) Lambs \#170-\#172were introduced from the National Agricultural Research Center for Hokkaido Region when they were 2 months old.

d) After experiment 4, lambs \#165 and \#167 were moved to the room in which sheep \#140 and \#143 were being kept.

e) Nasal washings from the OHV-2-positive sheep in experiments 2 and 3 were transferred to the nostrils of negative sheep.

f) Nasal washings from OHV-2-positive sheep in experiments 4 and 5 were transferred to the nostrils of negative sheep.

g) Age of the sheep at the beginning of the experiment. Y: year; M: month.

were divided into 3 groups, which were kept in 3 separate animal houses. To prevent contamination, caretakers changed their work wear and boots in between tending different groups. Four lambs were kept as negative controls to allow for the possibility of vertical infection. The other two groups (6 and 4 lambs, respectively) underwent the following transmission experiments (Table 1, Fig. 1).

Transmission via natural contact: Five experiments were conducted for transmission via natural contact. OvHV-2free sheep were housed in small rooms with OvHV-2infected sheep of different ages and sex. In experiment 1 , lamb \#146 (5 months old) was kept with infected wether \#955 (3 years old) for 8 months. In experiment 2, lamb \#116 (11 months old) was kept with infected ewe \#957 (3 years old), and the ewe gave birth 8 months later. This transmission experiment was discontinued because both the mother and the newborn lamb died of dystocia. However, sheep \#116 continued to be checked for OvHV-2 for an additional 5 months. In experiment 3, lambs \#140 and \#143 (9 months old) were kept with five pregnant infected ewes \#148-152 (7-8 years old), which gave birth 2 months later. All of the newborn lambs were removed within 5 days, and the experiment was continued for an additional 4 months. In experiment 4, three OvHV-2-infected lambs were chosen from among the 2-month-old lambs that had been raised under typical husbandry conditions with their flock at the National Agricultural Research Center for Hokkaido Region. At the time, it seemed that the transmission and spread of infection had been recent, based on the fact that about $50 \%$ of the 2 -month-olds in this flock were PCR positive. These three lambs, \#170-172 (3 months old), were transported to our institute and kept together with two nega- 


\section{1) Exp. 1}

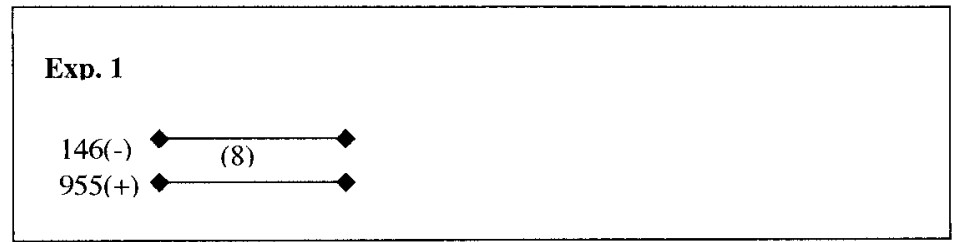

2) Exp. 2, 3, 6

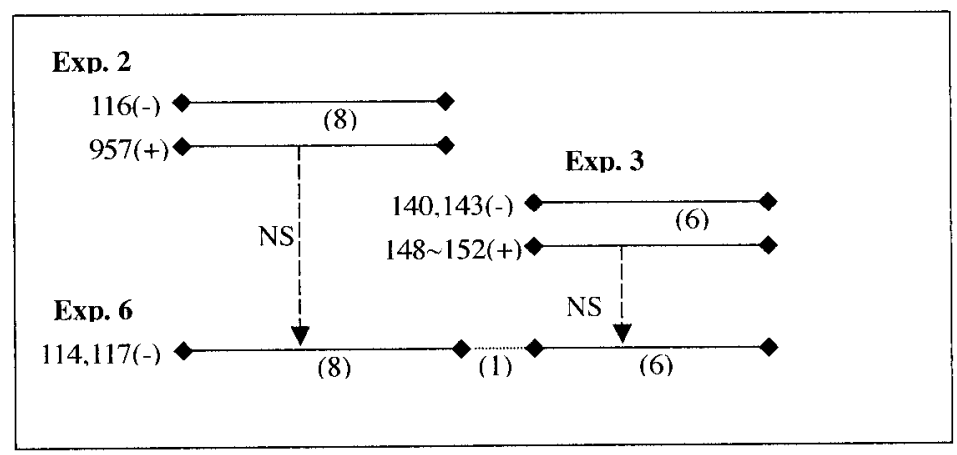

3) Exp. 4, 5, 7

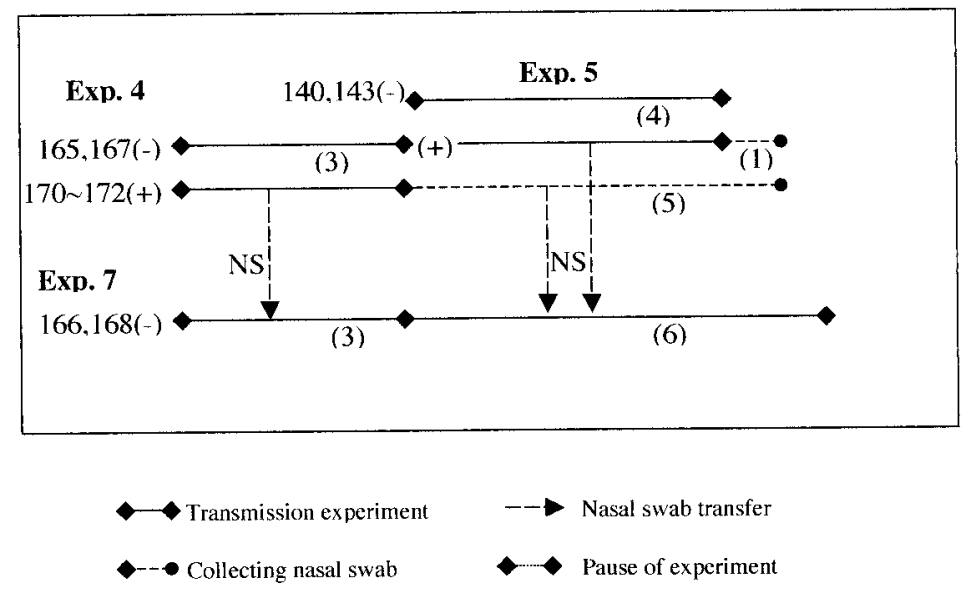

Fig. 1. Schema of the transmission experiments. The experiments in a group were carried out in parallel; namely, nasal washings were simultaneously collected in contact transmission experiments and used for nasal secretion transfer experiments. The figures in parentheses show the experimental period (month).

tive lambs \#165 and \#167 (4 months old). In experiment 5, lambs \#165 and \#167 (7 months old), which had been newly infected with OvHV-2 in experiment 4, were moved into a room where two negative sheep \#140 and \#143 (1.5 year old) were kept.

Transmission via nasal secretions: Nasal washings from OvHV-2-infected sheep were transferred to the nostrils of OvHV-2-free sheep as follows. A cotton swab was inserted into the nostrils of the OvHV-2-infected sheep, rubbed for few seconds, and then placed in $1.0 \mathrm{~m} l$ of phosphate-buff- ered saline. These cotton swabs were left for few minutes, agitated vigorously, and the excess fluid was expressed. Approximately $0.5 \mathrm{ml}$ of the fluid was inserted into the right nostril of the OvHV-2-free sheep. This procedure was repeated for 5 consecutive days at 4 -week intervals. In experiment 6, 2 sheep \#114 and \#117 (11 months old) received nasal washings from an infected ewe \#957, used in experiment 2 , for 8 months. Nasal washing transfer was discontinued for 1 month because ewe \#957 died, after which the 2 sheep received a nasal washing mixture from the 5 
Table 2. Appearance of OvHV-2 DNA in PBL and nasal swab in experiment on transmission by natural contact

\begin{tabular}{|c|c|c|c|c|c|c|c|c|c|c|c|c|c|c|c|c|}
\hline \multirow[t]{2}{*}{ Exp. No. } & \multirow[t]{2}{*}{ Sheep No. } & \multirow[t]{2}{*}{ Sample } & \multicolumn{13}{|c|}{ Weeks after the onset of contact } & \multirow[b]{2}{*}{13} \\
\hline & & & 0 & 1 & 2 & 3 & 4 & 5 & 6 & 7 & 8 & 9 & 10 & 11 & 12 & \\
\hline \multirow{10}{*}{4} & \multirow[b]{2}{*}{170 (Donor) } & PBL & $+^{\text {a) }}$ & + & + & + & + & + & + & + & + & + & + & + & + & + \\
\hline & & Nasal swab & -b) & - & + & + & + & + & $\mathrm{NT}^{\mathrm{c})}$ & + & + & + & + & + & + & NT \\
\hline & \multirow{2}{*}{171 (Donor) } & PBL & + & + & + & + & + & + & + & + & + & + & + & + & + & + \\
\hline & & Nasal swab & - & - & + & - & - & + & NT & - & + & + & + & + & - & NT \\
\hline & \multirow{2}{*}{172 (Donor) } & PBL & + & + & + & + & + & + & + & + & + & + & + & + & + & + \\
\hline & & Nasal swab & + & - & - & - & + & + & NT & - & - & + & + & + & - & NT \\
\hline & \multirow{2}{*}{165 (Recipient) } & PBL & - & - & - & - & - & - & - & - & - & - & + & + & + & + \\
\hline & & Nasal swab & - & - & - & - & - & - & - & - & + & + & - & - & - & - \\
\hline & \multirow[b]{2}{*}{167 (Recipient) } & PBL & - & - & - & - & - & - & - & - & - & - & + & + & + & + \\
\hline & & Nasal swab & - & - & - & - & - & - & - & - & + & + & + & - & - & + \\
\hline \multirow{8}{*}{5} & \multirow{2}{*}{165 (Donor) } & PBL & + & + & + & + & + & + & + & + & + & + & + & + & + & + \\
\hline & & Nasal swab & - & - & + & - & + & + & + & - & + & + & + & + & + & + \\
\hline & \multirow{2}{*}{167 (Donor) } & PBL & + & + & + & + & + & + & + & + & + & + & + & + & + & + \\
\hline & & Nasal swab & + & - & - & + & + & + & - & NT & + & + & - & + & + & - \\
\hline & \multirow{2}{*}{140 (Recipient) } & PBL & - & - & - & - & - & - & - & - & - & - & - & - & + & + \\
\hline & & Nasal swab & - & - & - & - & - & - & - & - & - & - & - & + & + & + \\
\hline & \multirow{2}{*}{143 (Recipient) } & PBL & - & - & - & - & - & - & - & - & - & - & - & - & + & + \\
\hline & & Nasal swab & - & - & - & - & - & - & - & - & - & - & - & - & + & - \\
\hline
\end{tabular}

a) PCR positive, b) PCR negative, c) Not tested.

positive ewes \#148-152, used in experiment 3 , for 6 months. In experiment 7, lambs \#166 (4 months old) and \#168 (3 months old) received a nasal washing mixture from the 3 positive lambs \#170-172, used in experiment 4, for 3 months, and then the nasal washing mixture from the 5 positive lambs \#170-172, \#165 and \#167, used in experiments 4 and 5.

Sample collection and PCR assay: Blood samples and nasal swabs were collected from all sheep at weekly intervals during each experimental period. In experiments 6 and 7 , nasal swabs were collected from the left nostril of the recipient sheep because nasal washings from the positive sheep had been placed in the right nostril. DNA was extracted from PBL using the commercial reagent, SapaGene (Sanko Jyun-yaku Co.Ltd., Tokyo), and DNA was also extracted from nasal swabs by the phenol-chloroformisoamylalcohol extraction method [9]. PCR assay was performed according to the method of Baxter et al. [1] with a slight modification to detect OvHV-2 genes [10].

\section{RESULTS}

Transmission via natural contact: In experiments 1-3, all of the donors for OvHV-2 showed PCR-positive at every test on their PBL, and at almost every test on their nasal swab (data not shown). After the OvHV-2-infected ewes in experiments 2 and 3 gave birth, the recipient lambs in the same rooms were checked for infection for an additional 5 months and 4 months, respectively. OvHV-2 was not transmitted to them during this time period.

In experiment 4, 2 negative lambs were kept with 3 lambs that had been recently infected with OvHV-2. After 8 weeks, the 2 lambs \#165 and \#167 showed PCR-positive on their nasal swabs. Two weeks later, they showed PCR-pos- itive on PBL (Table 2).

After it had been confirmed that these lambs were infected with the virus (13 weeks after the onset of contact), they were moved into a room in which 2 OvHV-2-free sheep were being kept (experiment 5). One of the sheep, \#140, showed PCR-positive on her nasal swab after 11 weeks, and both of the sheep, \#140 and \#143, showed PCR-positive on their PBL by the next week (Table 2).

Transmission via nasal secretions: In experiment 6, 2OvHV-2-free sheep received nasal washings from the adult ewes in experiments 2 and 3, and OvHV-2 was not found to be transmitted. In experiment 7 , one of the recipient lambs, \#166, was infected with OvHV-2 after 6 months (Table 3). The timing was parallel with the infection of sheep \#140 and 143 in the contact experiment. The 2 recipient lambs in experiment 7 had been kept together up to that time. Subsequent to \#166 showing positive, another recipient lamb, \#168, was immediately moved into a separate room, and continued to be administered the nasal washing mixture. Two months later, lamb \#168 was found to be infected with OvHV-2.

\section{DISCUSSION}

In contrast with AlHV-1, OvHV-2 congenital infection hardly occurs in sheep. Li et al. [12] reported that lambs could be raised free of the virus when they were separated from the flock at 2.5 months of age. On the other hand, Baxter et al. [2] reported that lambs were infected at very young ages of under 2 months. In our unpublished data, most lambs in a flock became infected with OvHV-2 between 2 and 6 months after birth; however, all the lambs born in the flock the next year were infected within 1 month after birth. Thus, infection rates for OvHV-2 might be inconstant even 
Table 3. Appearance of OvHV-2 DNA in PBL and nasal swab in experiment on transmission by the transfer of nasal secretions

\begin{tabular}{|c|c|c|c|c|c|c|c|c|c|c|c|}
\hline \multirow[t]{2}{*}{ Exp. No. } & \multirow[t]{2}{*}{ Sheep No. } & \multirow[t]{2}{*}{ Sample } & \multicolumn{9}{|c|}{ Period for receiving nasal washings (months) } \\
\hline & & & 1 & 2 & 3 & 4 & 5 & 6 & 7 & 8 & 9 \\
\hline \multirow[t]{4}{*}{7} & \multirow{2}{*}{166 (Recipient) $^{\mathrm{a})}$} & PBL & - b) & - & - & - & - & $t^{\mathrm{c})}$ & + & + & + \\
\hline & & Nasal swab & - & - & - & - & - & + & + & + & + \\
\hline & \multirow{2}{*}{$168{\text { (Recipient })^{\mathrm{a})}}$} & PBL & - & - & - & - & - & - & - & + & + \\
\hline & & Nasal swab & - & - & - & - & - & - & - & - & + \\
\hline
\end{tabular}

a) OvHV-2-negative sheep received nasal washing mixture from the three positive sheep (\#170-172), used in experiment 4, for 3 months, and then from the five positive sheep (\#170-172,\#165, and \#167) in experiments 4 and 5.

b) PCR negative .

c) PCR positive.

in the same flock. Similarly, Li et al. [13] recently reported that infection rates for OvHV-2 varied among groups of sheep. Therefore, we separated newborn lambs from their mothers within 5 days after birth and raised them by bottlefeeding in order to produce OvHV-2-free lambs.

Li et al. $[14,15]$ reported on the transmission of OvHV-2 among lambs and/or adult sheep in flock conditions. They showed that adult sheep had the ability to transmit the virus in the flock. In their experiments, 12 negative adult sheep were housed with 11 positive adult sheep, ranging from 3 to 6 years old. All of the negative sheep became PCR-positive during 4 and 12 months post-mixing [15]. We tried to evaluate the possibility of transmission between individual sheep in smaller group conditions. In our results, it seemed that adult sheep did not transmit OvHV-2 as easily as did recently infected lambs. Though all of the adult sheep showed PCR-positive on their PBL, they did not transmit the virus to the negative lambs. In addition, even the ewes that gave birth during the experimental period did not transmit. In contrast, when negative sheep were kept with recently infected lambs, they were infected within 3 months of the onset of contact.

Mushi et al. [17] reported that AlHV-1 was isolated from nasal and ocular secretions of wildebeest calves up to 3 months of age; thereafter, the virus could not be isolated from these secretions. It is assumed that infected sheep may intensively shed OvHV-2 during a certain period after their primary infection as is the case with AlHV-1-infected wildebeest.

We attempted to confirm the transmission routes of OvHV-2 in this study. Li et al. [15] reported that whole blood from infected sheep was able to transmit the virus, but it was much less efficient than contact exposure. Although some researchers have reported that a higher number of copies of OvHV-2 DNA can be detected in nasal secretions than in PBL $[6,11]$, it has not yet been confirmed that nasal secretions contain the infectious virus. In our experiments, nasal washings from OvHV-2-infected sheep were transferred to the nostrils of negative sheep. As in the contact experiments, transmission of the virus by adult sheep did not occur, while transmission by recently infected lambs was successful. However, it took 6-8 months for the status of the recipient sheep to convert to PCR-positive. This was a much longer period than that of contact transmission. It might be caused by less frequency of exposure to the virus, since we transferred nasal washings for only 5 consecutive days at 4 -week intervals. Nonetheless, it was interesting that the negative sheep \#140, 143 and 166 in experiment 5 and 7 were infected at the almost same time. It was supposed that the donor lambs in experiment 5 might sufficiently shed infectious virus in their nasal secretions. On the other hand, \#168 was infected 2 months later than \#166. This might be caused by differences of sensitivity among individual sheep. But the possibility of contact transmission from \#166 in this experiment could not be denied, whereas \#168 was immediately separated from \#166 just after \#166 was infected with the virus.

Though we did not attempt other transmission routes in this study, there have been several reports that no OvHV-2 DNA was detected in the urinary bladder [2], urine or faeces $[7,8]$. Consequently, it is suggested that nasal secretions play an active role in transmission of the virus among sheep. In addition, when the lambs were primarily infected with the virus in our experiments, viral DNA was first detected in most individual's nasal swabs 1 or 2 weeks before being detected in PBL. It is therefore supposed that the nasal cavity is a portal of entry and shedding of infectious OvHV-2 in sheep.

Although the number of animals in this study was limited, this is the first report to reveal that nasal secretions contain infectious OvHV-2 and to demonstrate that the infectivity of the virus depends on the age (or time after infection) of the host. These results will contribute to an understanding of the transmission mechanism of OvHV-2 and to the control of SA-MCF.

\section{REFERENCES}

1. Baxter, S. I. F., Pow, I., Bridgen, A. and Reid, H. W. 1993. PCR detection of the sheep-associated agent of malignant catarrhal fever. Arch. Virol. 132: 145-159.

2. Baxter, S. I. F., Wiyono, A., Pow, I. and Reid, H. W. 1997. Identification of ovine herpesvirus-2 infection in sheep. Arch. Virol. 142: 823-831.

3. Bridgen, A. and Reid, H. W. 1991. Derivation of a DNA clone 
corresponding to the viral agent of sheep-associated malignant catarrhal fever. Res. Vet. Sci. 50: 38-44.

4. Buxton, D. and Reid, H. W. 1980. Transmission of malignant catarrhal fever to rabbits. Vet. Rec. 106: 243-245.

5. Herring, A., Reid, H., Inglis, N. and Pow, I. 1989. Immunoblotting analysis of the reaction of wildebeest, sheep and cattle sera with the structural antigens of Alcelaphine herpesvirus-1 (malignant catarrhal fever virus). Vet. Microbiol. 19: 205-215.

6. Hua, Y., Li, H. and Crawford, T. B. 1999. Quantitation of sheep-associated malignant catarrhal fever viral DNA by competitive polymerase chain reaction. J. Vet. Diagn. Invest. 11: $117-121$.

7. Hussy, D., Janett, F., Albini, S., Stäuber, N., Thun, R. and Ackermann, M. 2002. Analysis of pathogenetic basis for shedding and transmission of ovine gamma herpesvirus 2. J. Clin. Microbiol. 40: 4700-4704.

8. Hussy, D., Stauber, N., Leutenegger, C.M., Rieder, S. and Ackermann, M. 2001. Quantitative fluorogenic PCR assay for measuring ovine herpesvirus 2 replication in sheep. Clin. Diagn. Lab. Immunol. 8: 123-128.

9. Imai, K., Mase, M., Yamaguchi, S., Yuasa, N. and Nakamura, K. 1998. Detection of chicken anaemia virus DNA from formalin-fixed tissues by polymerase chain reaction. Res. Vet. Sci. 64: $205-208$

10. Imai, K., Nishimori, T., Horino, R., Kawashima, K., Murata, H., Tsunemitsu, H., Saito, T., Katsuragi, K. and Yaegashi, G. 2001. Experimental transmission of sheep-associated malignant catarrhal fever from sheep to Japanese deer (Cervus Nippon) and cattle. Vet. Microbiol. 79: 83-90.

11. Li, H., Hua, Y., Snowder, G. and Crawford, T. B. 2001. Levels of ovine herpesvirus 2 DNA in nasal secretions and blood of sheep: imprecations for transmission. Vet. Microbiol. 79: 301310 .
12. Li, H., Snowder, G. D. and Crawford, T. B. 1999. Production of malignant catarrhal fever virus-free sheep. Vet. Microbiol. 65: $167-172$.

13. Li, H., Snowder, G. D. and Crawford, T. B. 2002. Effect of passive transfer of maternal immune components on infection with ovine herpesvirus 2 in lambs. Am. J. Vet. Res. 63: 631633.

14. Li, H., Snowder, G., O'Toole, D. and Crawford, T. B. 1998. Transmission of ovine herpesvirus 2 in lambs. J. Clin. Microbiol. 36: 223-226.

15. Li, H., Snowder, G., O'Toole, D. and Crawford, T. B. 2000. Transmission of ovine herpesvirus 2 among adult sheep. Vet. Microbiol. 71: 27-35.

16. Mushi, E. Z. and Rurangirwa, F. R. 1981. Epidemiology of bovine malignant catarrhal fevers, a review. Vet. Res. Commun. 5: 127-142.

17. Mushi, E. Z., Rurangirwa, F. R. and Karstad, L. 1981. Shedding of malignant catarrhal fever virus by wildebeest calves. Vet. Microbiol. 6: 281-286.

18. Plowright, W. 1965. Malignant catarrhal fever in East Africa. I. Behaviour of the virus in freeliving populations of blue wildebeest (Gorgon taurinus taurinus, Burchell). Res. Vet. Sci. 6: 5668.

19. Plowright, W. 1965. Malignant catarrhal fever in East Africa. II. Observations on wildebeest calves at the laboratory and contact transmission of the infection to cattle. Res. Vet. Sci. 6: 69-83.

20. Plowright, W. 1990. Malignant catarrhal fever virus. pp. 123150. In: Virus Infections of Ruminants (Dinter, Z. and Morein, B. eds.), Elsevier Science, New York.

21. Plowright, W., Ferris, R. D. and Scott, G. R.1960. Blue wildebeest and the aetiological agent of bovine malignant catarrhal fever. Nature (Lond.) 188: 1167-1169. 